\title{
Genotype-phenotype correlation in vascular Ehlers-Danlos syndrome: Novel duplication mutation of COL3A1 gene in a large pedigree
}

\author{
Márta Medvecz ${ }^{1}$, György Fekete ${ }^{2}$, Balázs Mayer ${ }^{1}$ and Sarolta Kárpáti ${ }^{1}$ \\ ${ }^{1}$ Department of Dermatology, Venerology and Dermatooncology, Semmelweis University, Budapest, Hungary \\ $22^{\text {nd }}$ Department of Paediatrics, Semmelweis University, Budapest, Hungary
}

\section{Introduction}

Vascular Ehlers-Danlos syndrome (vEDS, EDS type IV, OMIM 130050) is a rare autosomal dominantly inherited connective tissue disorder characterized by generalized connective tissue fragility. Affected individuals are at risk of arterial rupture, aneurysm, or dissection; gastrointestinal perforation or rupture; and uterine rupture during pregnancy. The disease is caused by structural defects in the proa1(III) chain of collagen type III encoded by the COL3A1 gene.

Here we present a VEDS patient with complex severe clinical symptoms. We investigated genomic DNA sample of VEDS index patient with full-gene Sanger sequencing of COLZA1 gene.

\section{Material and methods}

\section{Phenotype of the index patient}

A 42-year-old female patient was investigated with thin, translucent and slightly extensible skin, with highly visible subcutaneous vessels, characteristic facial appearance with blue sclera, gingival recession, small joints hypermobility, acrogeria, generalized vascular fragility, hemothorax, pes planus and scoliosis.
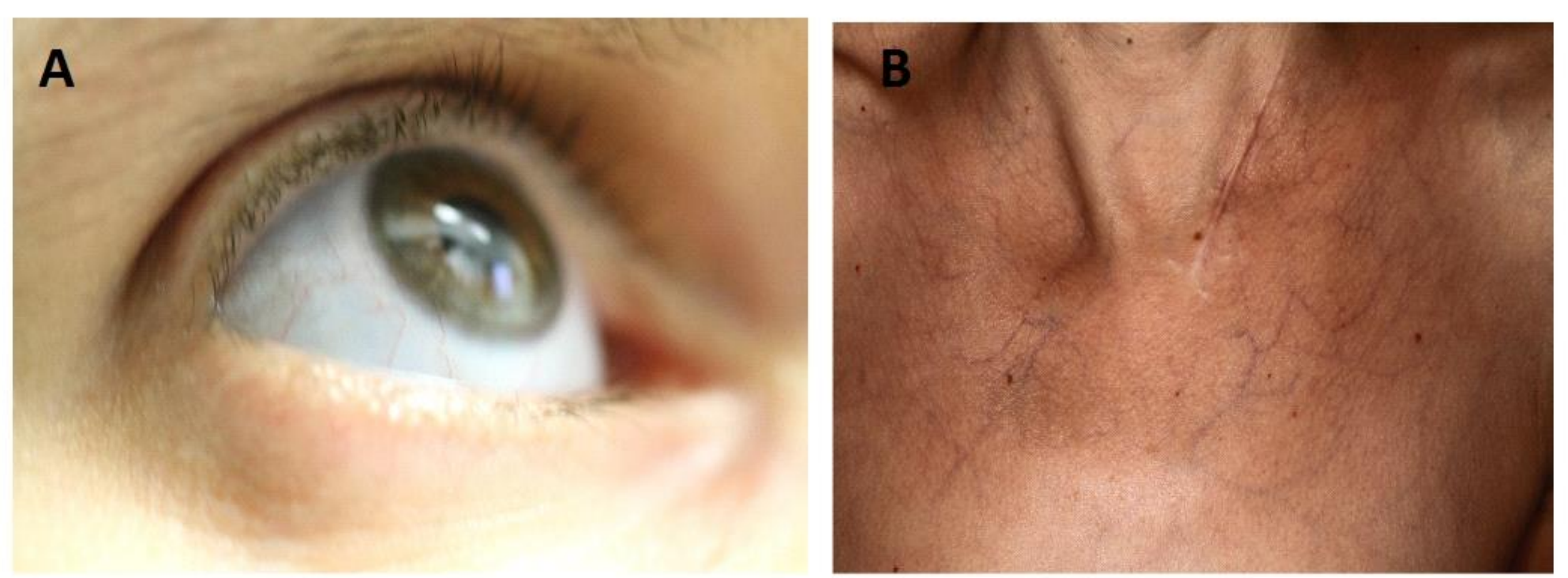

A: blue sclera

B: thin, translucent

skin with highly

visible subcutaneous vessels
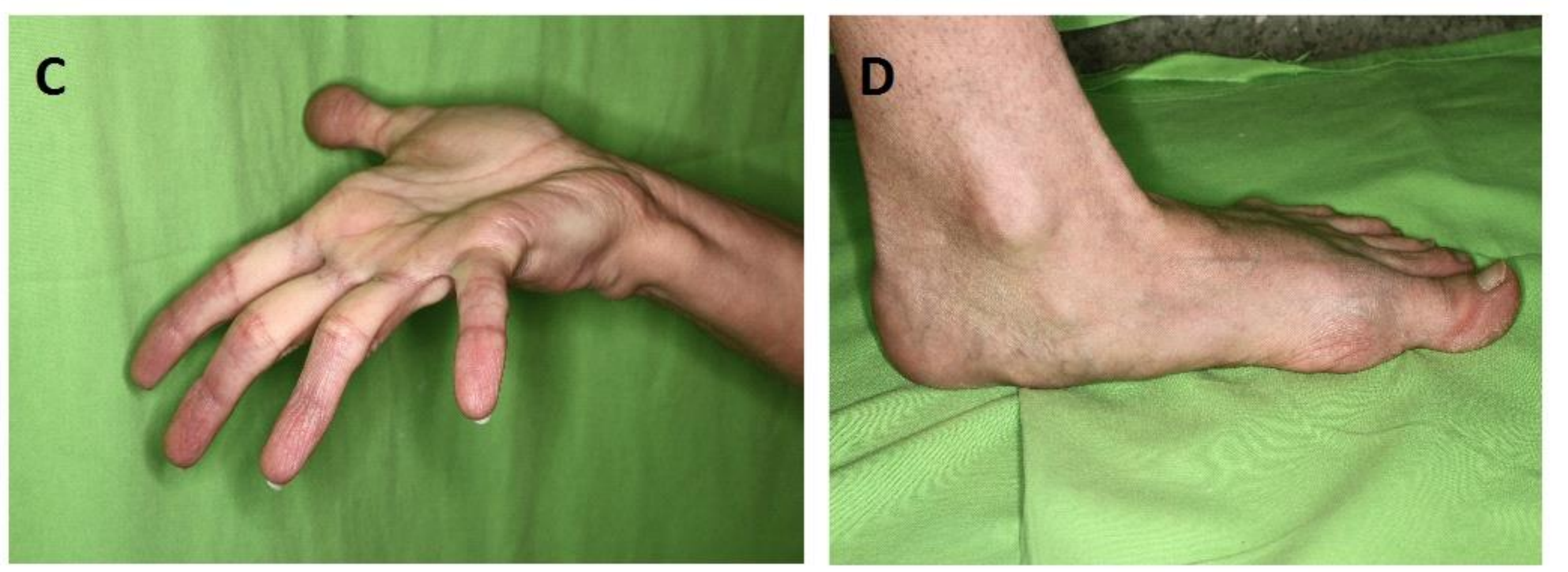

\section{C: hypermobility of}

small joints and

acrogeria

D: pes planus

\section{Pedigree analysis diagram}

The pedigree analysis of the index patient (III/5.) suggest autosomal dominant inheritance and the VEDS phenotype appears three generation.

I.

\section{II.}

III.

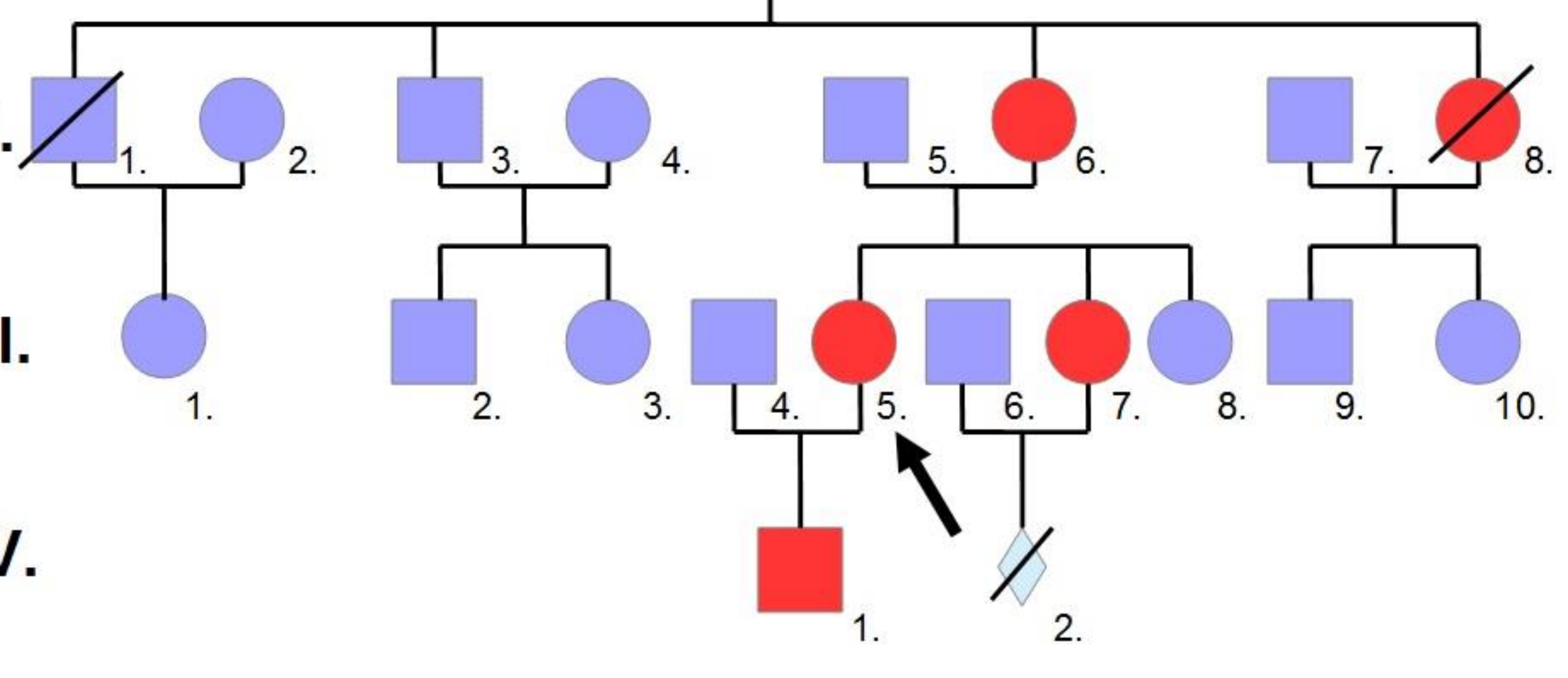

\section{Methods}

- Isolation of genomic DNA from peripheral blood leukocytes

- Full-gene Sanger sequencing of COL3A1 gene (OMIM 120180) (CENTOGENE Rostock)

- In silico analyses (Exome Aggregation Consortium, Exome Sequencing Project, 1000 Genomes Browser)

- Family screening by Sanger sequencing (exon 43 of COL3A1 gene)

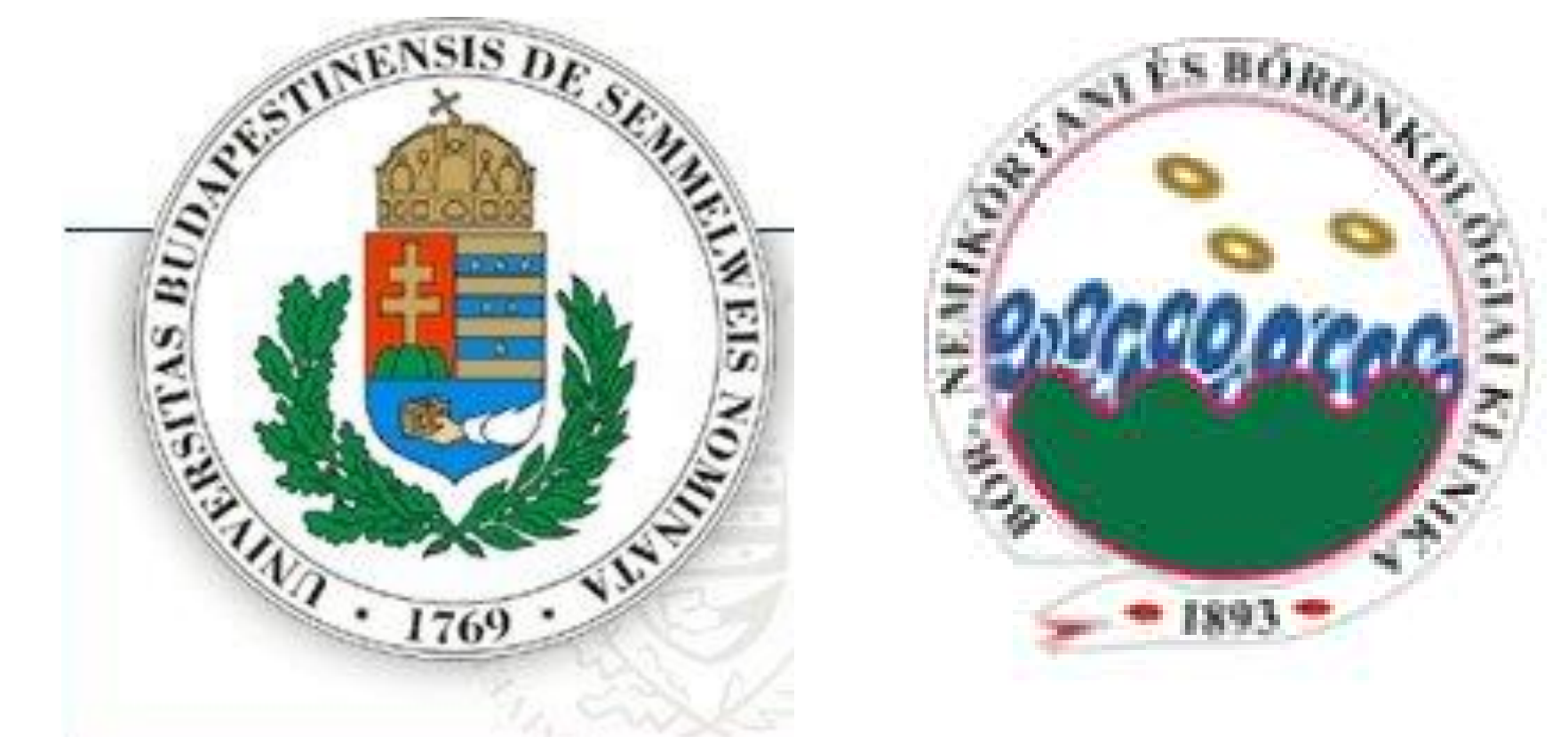

Results

We detected a previously unreported heterozygous variant of COLBA1 gene, c.3124_3141dup (p.Ala1042_Gly1047dup). The duplication of that 18 bp causes duplication of 6 residues including two glycines within the triplehelical region (Ala-ProGly-Ala-Pro-Gly) of the type III procollagen molecule.

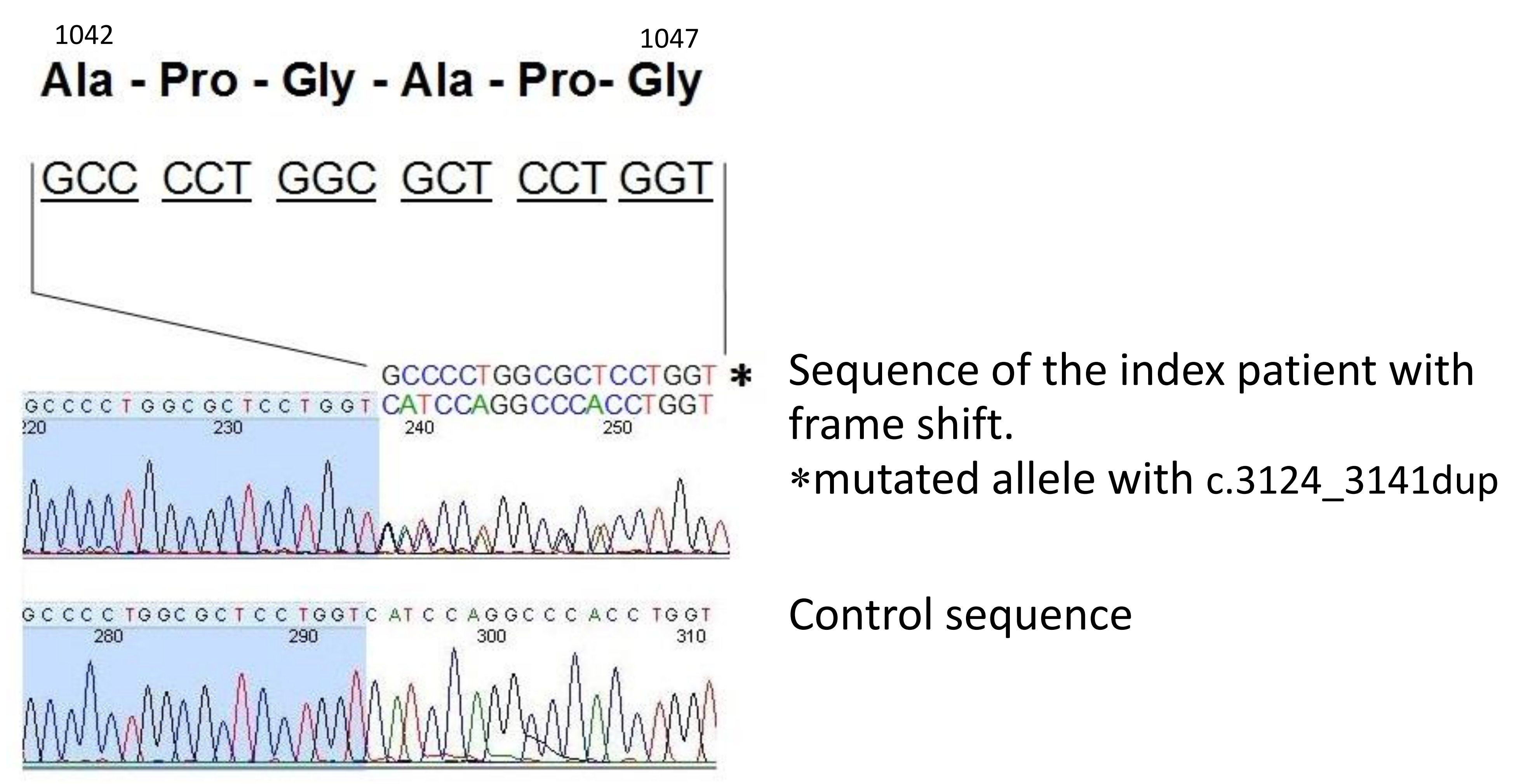

\section{Genotype-phenotype correlation study}

\begin{tabular}{|c|c|c|c|c|}
\hline $\begin{array}{l}\text { Pedigree } \\
\text { patient ID }\end{array}$ & $\begin{array}{c}\text { Skin } \\
\text { manifestation }\end{array}$ & $\begin{array}{l}\text { Extracutaneous } \\
\text { manifestations }\end{array}$ & Phenotype & Genotype \\
\hline $1 / 2$ & - & - & - & wild type/wild type \\
\hline $11 / 5$. & - & - & - & wild type/wild type \\
\hline $11 / 6$ & $\begin{array}{l}\text { Thin, } \\
\text { translucent } \\
\text { skin; } \\
\text { acrogeria }\end{array}$ & $\begin{array}{l}\text { Joint } \\
\text { hypermobility; } \\
\text { facial appearance; } \\
\text { blue sclera }\end{array}$ & VEDS & $\begin{array}{l}\text { Heterozygous } \\
\text { c.3124_3141dup/ } \\
\text { wild type }\end{array}$ \\
\hline III/4. & - & - & - & wild type/wild type \\
\hline III/5. & $\begin{array}{l}\text { Thin, } \\
\text { translucent } \\
\text { skin; extensive } \\
\text { bruising; } \\
\text { acrogeria }\end{array}$ & $\begin{array}{l}\text { Arterial rupture; } \\
\text { hemothorax; } \\
\text { facial appearance; } \\
\text { blue sclera; } \\
\text { gingival recession; } \\
\text { joint } \\
\text { hypermobility; } \\
\text { pes planus; } \\
\text { scoliosis }\end{array}$ & vEDS & $\begin{array}{l}\text { Heterozygous } \\
\text { c.3124_3141dup/ } \\
\text { wild type }\end{array}$ \\
\hline III/6. & $\begin{array}{l}\text { Thin, } \\
\text { translucent } \\
\text { skin; extensive } \\
\text { bruising; } \\
\text { acrogeria; } \\
\text { psoriasis }\end{array}$ & $\begin{array}{l}\text { Intrapartum } \\
\text { uterine rupture; } \\
\text { facial appearance; } \\
\text { blue sclera; } \\
\text { joint } \\
\text { hypermobility; } \\
\text { Scoliosis }\end{array}$ & vEDS & $\begin{array}{l}\text { Heterozygous } \\
\text { c.3124_3141dup/ } \\
\text { wild type }\end{array}$ \\
\hline III/10. & - & - & - & wild type/wild type \\
\hline IV/1. & $\begin{array}{l}\text { Thin, } \\
\text { translucent } \\
\text { skin }\end{array}$ & $\begin{array}{l}\text { Blue sclera; } \\
\text { facial appearance; } \\
\text { pes planus; } \\
\text { scoliosis }\end{array}$ & vEDS & $\begin{array}{l}\text { Heterozygous } \\
\text { c.3124_3141dup/ } \\
\text { wild type }\end{array}$ \\
\hline
\end{tabular}

\section{Conclusions}

The novel duplication mutation co-segregated with the vEDS-phenotype in the large family of the index patient.

This previously unpublished insertion in the COL3A1 gene expands the spectrum of mutations underlying vEDS and helps to perform genetic counselling. 